\title{
Medication charts in residential aged-care facilities
}

\section{John Jackson}

Director, Project Pharmacist Faculty of Pharmacy and Pharmaceutical Sciences Monash University

Melbourne

\section{Elspeth Welsh \\ Pharmacist \\ Epic Pharmacy \\ Brisbane}

\section{Keywords}

aged, medication errors, National Residential

Medication Chart

Aust Prescr 2017;409:20-2 http://dx.doi.org/10.18773/ austprescr.2017.004

\section{SUMMARY}

An aged-care facility should maintain a current, accurate and reliable record of the drugs prescribed and given to a resident. The correct use of a medication chart can meet this requirement.

The hard-copy National Residential Medication Chart aims to provide a standard form for the prescription, dispensing and administration of drugs. In addition to providing a comprehensive record, it should facilitate communications between health professionals who are unlikely to visit aged-care facilities at the same time.

The chart will also enable pharmacists to supply most drugs without the need for a separate prescription. This should reduce transcription errors and avoid delays in the supply of medicines.

There are concerns about the efficiency of using the chart. These could possibly be addressed if an electronic version was developed.

\section{Introduction}

A medication chart in a residential aged-care facility serves as a communication tool between doctors, nurses, pharmacists, other health professionals and hospitals regarding a resident's medicines. It is used to direct how and when drugs are to be administered and as a record of their administration.

There are almost 3000 aged-care facilities in Australia with approximately 200000 residents.' With an average of 9.75 medications per resident, polypharmacy (defined as the concurrent use of five or more drugs) is widespread. ${ }^{2}$ The Department of Health has published 'Guiding principles for medication management in residential aged care facilities'. ${ }^{3}$ This states that 'facilities should ensure all residents have a current, accurate and reliable record of all medicines selected, prescribed and used, to support safe prescribing and administration'. The correct use of an appropriately designed medication chart, either hard copy or electronic, addresses this requirement.

Most facilities use proprietary printed medication charts available from commercial printers, agedcare service companies, or electronic versions from agencies whose charts are able to be printed on site.

\section{Issues with medication charts in residential aged care}

The proprietary printed charts used in aged-care facilities are usually multiple-page booklets designed to last for periods of up to six months. Whereas patients, doctors, nurses and pharmacists are usually co-located in hospitals and can physically use the same chart, this is not the case in residential aged-care facilities. Their differing locations result in all paperwork needing to be copied and faxed or shared electronically between the facility, doctors and pharmacists. The multiple-page booklet format of the charts used in aged care complicates transmitting a comprehensive record of a resident's current treatments.

Drugs can be supplied to residents of aged-care facilities in original packs dispensed by a pharmacist and labelled with instructions for administration or supplied in dose administration aids. These aids may be packed with a single drug per pack (unit dose) or with a number of drugs due to be simultaneously administered to the resident (multi dose). While dose administration aids have become common place in aged-care facilities, not all prescribed drugs can be packed together due to formulation, stability or regulatory restraints. This frequently results in the use of parallel supply systems of original packs and dose administration aids.

All jurisdictions require a registered or enrolled nurse to be responsible for the drugs given in a residential aged-care facility. However, in some circumstances, trained nursing assistants are able to help residents to self-administer medicines. ${ }^{4}$ If supplied in an original pack, the nurse who administers a drug is required to verify it against the doctor's order, select the correct quantity and record the administration on the chart. If the drug is supplied in a dose administration aid, the staff member who assists a resident to self-administer or who administers the contents must sign for doing so without the responsibility of identifying each drug. 
Medication charts need to be able to accommodate these differences in packaging and the obligations for documentation.

Any scheduled drug ordered on a medication chart in a residential aged-care facility requires a separate prescription to be written to facilitate supply and, if the medicine is listed on the Pharmaceutical Benefits Scheme (PBS), to enable reimbursement of the pharmacist. There are risks associated with the duplication of a written medication order. There are also additional 'clerical' obligations and a potential for a delay in treatment. Any tardiness in writing a complete prescription may entail a delay in supply or payment and, if the prescription is never written, there will be no reimbursement of the cost.

\section{Electronic advances}

Studies have shown that the implementation of electronic medication management systems which link residential aged-care facilities with prescribers and pharmacists improves clarity and accuracy, provides efficiency and enhances safety. ${ }^{5,6}$ The systems were developed as tools to record and report on drug administration, but now include sharing of real-time data on adherence and changes to treatment, and the ordering of stock. The electronic version of the doctor's order displays just the current drugs resulting in a much simpler document than the proprietary printed charts. Administration sign-off can be paper-based or completed electronically.

\section{The National Residential Medication Chart}

The fifth Community Pharmacy Agreement between the Department of Health and the Pharmacy Guild of Australia funded the development of a system for supply and claiming of PBS medicines from a standardised medication chart in residential agedcare facilities without the need for a separate prescription. ${ }^{7}$ This initiative was intended to reduce the administrative burden for prescribers, pharmacists and staff by improving the timeliness of prescribing and dispensing and minimising the duplication of effort for the resident's healthcare team. ${ }^{7}$ The concept should enhance medication safety by reducing the risk of transcription errors that arise from the need to write drug orders twice - once on the chart and again on the prescription.

The Australian Commission on Safety and Quality in Health Care was engaged to develop a medication chart that would incorporate the required data. ${ }^{8}$ This project was informed by the long-standing work of the Commission in developing the National Inpatient Medication Chart and supplementary charts. These are a nationally consistent set of paper- based medication charts (with some available in an electronic format), which aim to enhance patient safety through the widespread use of standard, evidence-based charts. ${ }^{9,10}$

The development of the National Residential Medication Chart addressed the sections, layout, functionality and duration of the chart. Evaluation in 22 aged-care facilities demonstrated significant reductions in medication administration errors and less incorrect packaging of residents' medicines."

Legislative changes have been made in all jurisdictions enabling the use of a compliant medication chart, such as the National Residential Medication Chart, for prescribing, dispensing and claiming purposes. The National Residential Medication Chart is at this stage paper-based, however there is potential for software providers to develop an electronic option.

\section{Format}

The National Residential Medication Chart is a 52-page landscape format booklet that includes sections for patient and practitioner identification, resident assessment, allergy, weight and blood glucose documentation. ${ }^{12}$ It is intended to last for four months. Space is provided for ordering and recording the administration of 11 regular drugs, eight short-term drugs, six 'when-required' drugs, three nurse-initiated medicines and six phone orders. There can be three warfarin orders (or other variable dose drugs) with related pathology instructions and results, three regular insulin orders and four 'whenrequired' insulin orders. The chart also includes space for recording nutritional supplementation and supply to residents from dose administration aids.

Supporting information printed on the National Residential Medication Chart includes instructions on the use of the chart, common abbreviations, advice regarding PBS regulations and checklists for the safe administration of drugs. Colour has been used extensively to differentiate sections of the chart. If an order is written on the National Residential Medication Chart in accordance with the regulations, the majority of PBS-listed drugs can be dispensed without the need for a separate prescription. However, a prescription is still required for PBS Authority items requiring prior approval, PBS Section 100 items, controlled drugs (Schedule 8 medicines) and extemporaneously compounded medicines. ${ }^{8}$

As the order for a drug written on the National Residential Medication Chart is for both administration and supply, the doctor is required to include a start date and an indication of the duration of treatment. Streamlined authority code, 'Closing the Gap' identification and brand substitution are required if applicable. ${ }^{8}$ 


\section{Implementation}

The National Residential Medication Chart incorporates some of the medicine safety principles of the National Inpatient Medication Chart. However, the desired safety and efficiency outcomes will only be achieved if residential aged-care facilities and health professionals find the National Residential Medication Chart easy to use. Practitioners, and companies printing drug therapy charts, report that there has been limited implementation of the National Residential Medication Chart. This may be due to factors identified by residential aged-care staff, including:

- increased medication round times as a result of having to move back and forward through the many pages and different sections of the chart

- increased potential to miss drugs or a change of dose if they are written in different sections

- the cost of printing a chart incorporating many colours

- the time to communicate changes to the pharmacy as a result of needing to copy and fax a minimum of 12 pages

- the need for doctors to handwrite all entries, including sections required by the PBS that would otherwise be generated automatically in their prescription software

- the need for doctors to rewrite the whole chart every four months

- the need for pharmacists to maintain a copy of at least 22 pages of the chart, access the correct page in order to record ongoing dispensing of an item, annotate the copy with details of each item dispensed, cease PBS dispensing when the chart is four months old, and continue to access hard-copy PBS scripts for specific drugs.
Some of the identified factors are not specific to the National Residential Medication Chart and relate to changes in practice associated with the new format and processes. Due to the range of health professionals and the significant changes involved, implementation of the National Residential Medication Chart requires a detailed change management process. The Australian Commission on Safety and Quality in Health Care has prepared user guides for staff and health professionals. ${ }^{8}$

\section{Conclusion}

Some of the inefficiencies and risks associated with the ordering and supply of drugs in residential aged-care facilities, arising from the external location of doctors and pharmacists, are resolved by the capacity to work from a single data source in the form of the National Residential Medication Chart. Problems associated with implementation of the chart may be due to both the format of the chart and the change in practices associated with its use. An electronic version of the National Residential Medication Chart may address the operational problems that have been noted with the introduction of the paper version. $<$

Elspeth Welsh is employed by Epic Pharmacy which provides services to residential aged-care facilities. At the time of writing John Jackson was also employed by Epic Pharmacy.

John Jackson was a member of the Australian Commission on Safety and Quality in Health Care advisory committees for the National Residential Medication Chart program and has been involved with committees which developed and maintain the National Inpatient Medication chart and related charts.

\section{REFERENCES}

1. Australian Government Department of Health. Ageing and aged care. Total number of operational aged care facilities and services by service type by state and territory - 30 June 2016. https://agedcare.health.gov.au/news-andresources/publications/research-and-statistics/total-number-of-operationalaged-care-facilities-and-services-by-service-type-by-state-and-territory-30june-2016 [cited 2017 Jan 9]

2. Somers M, Rose E, Simmonds D, Whitelaw C, Calver J, Beer C. Quality use of medicines in residential aged care. Aust Fam Physician 2010:39:413-6.

3. Australian Government Department of Health. Guiding principles for medication management in residential aged care facilities - 2012 http://www.health.gov.au/internet/main/publishing.nsf/content/nmp-pdfresguide-cnt.htm [cited 2017 Jan 9]

4. Australian Nursing and Midwifery Federation. Nursing guidelines: management of medicines in aged care. Melbourne: ANMF; 2013.

5. Burns P, Perkins D, Larsen K, Dalley A. The introduction of electronic medication charts and prescribing in aged care facilities: an evaluation. Australas J Ageing 2007;26:131-4. http://dx.doi.org/10.1111/j.1741-6612.2007.00237.x

6. Bollen C, Warren J, Whenan G. Introduction of electronic prescribing in an aged care facility. Aust Fam Physician 2005;34:283-7.
7. Australian Government and the Pharmacy Guild of Australia. The fifth community pharmacy agreement between the Commonwealth of Australia and the Pharmacy Guild of Australia. http://6cpa.com.au/about-6cpa [cited 2017 Jan 9]

8. Australian Commission on Safety and Quality in Health Care. National Residential Medication Chart. www.safetyandquality.gov.au/our-work/ medication-safety/medication-chart/nrmc [cited 2017 Jan 9]

9. Australian Commission on Safety and Quality in Health Care. Medication charts. NIMC for adult patients. WWW.safetyandquality.gov.au/our-work/ medication-safety/medication-chart/nimc [cited 2017 Jan 9]

10. Coombes ID, Reid C, McDougall D, Stowasser D, Duiguid M, Mitchell C. Pilot of a National Inpatient Medication Chart in Australia: improving prescribing safety and enabling prescribing training. Br J Clin Pharmacol 2011;72:338-49. http://dx.doi.org/10.1111/j.1365-2125.2011.03967.x

11. Australian Commission on Safety and Quality in Health Care. Phased implementation of the National Residential Medication Chart in NSW residential aged care facilities: evaluation report. Sydney: ACSQHC; 2014.

12. Australian Commission on Safety and Quality in Health Care. Nationa Residential Medication Chart v.3. Sydney: ACSQHC. www.safetyandquality.gov.au/wp-content/uploads/2012/02/ NRMC-v3-high-resolution-printer-file.pdf [cited 2017 Jan 9] 